\title{
Press Coverage of Electoral Politics: A Study of Indian Parliamentary Elections in two Mainstream Dailies
}

\author{
Dr. Mohd Anas*
}

Researcher in media and communication studies

DOI: $10.36347 /$ sjahss.2020.v08i05.005

| Received: 04.05.2020 | Accepted: 12.05.2020 | Published: 30.05.2020

*Corresponding author: Dr. Mohd Anas

Abstract

The mass media are the carrier of social, political, economic and moral messages to the pervasive populace spread over vast geographical areas with different priorities, practices, mindsets, ego sets and moral or ethical values. The ultimate objectives of the promoters of these messages is to communicate and educate people about socio-political, socio-cultural, socio-ethical and socio-economic development to an information-hungry citizenry that can build an independent, egalitarian, stable, civilized and peaceful state failing which media tend to lose their relevance and significance in a millennium in which, the human race so desperately depends upon them. In this age of information and communication technology, media provide the latest \& erudite means of expression facilitating rapid and rabid communication connecting people across the world. Media vehicles are the most popular platforms performing as the facilitator of the free and fair elections and socio-politically accountable gatekeepers to safeguard the transparency in the democratic system. In a democracy different poll players participate in political debate and discussions to explore the adequate information about poll activities, political parties, policies and issues where elections without media freedom considered a contradiction to standardised norms. This paper aims at exploring media attributes in reporting general elections of 2014 with reference to their coverage to various political entities. The paper examines the media responsibilities in a democracy and provides comparative reporting tendencies in Indian media during the general elections of 2014.

Keywords: Media, Communication, Elections, Democracy, Politics, Parties.

Copyright @ 2020: This is an open-access article distributed under the terms of the Creative Commons Attribution license which permits unrestricted use, distribution, and reproduction in any medium for non-commercial use (NonCommercial, or CC-BY-NC) provided the original author and source are credited.

\section{INTRODUCTION}

According to Jaishri N Jethwany, a campaign is an audience concentrated short-term communication program operated through the application of modern media means. The masses are not identical groups due to their heterogeneity and non-cohesive structures [1]. Therefore, this modern age belongs to mediated communication enabled through indirect or impersonal sophisticated media instruments [2]. In this world, media play a crucially significant role in the political sphere with its far-reaching impacts and imprints influencing public opinion through its agenda-setting role [3]. Media describe and interpret the issues of ultimate public relevance that emerge as dominant and decisive factors in the political discourse. It acts as a gatekeeping agent to provide a measure to check on the political system in order to ensure transparency. An independent media mechanism is an effective instrument that keeps democracy on track and, therefore, cast an affirmative appeal among its citizens under the spirit of democracy [4]. With the advent and proliferation of the new media in modern time media has become more powerful like never before. The robust technology-driven modern media has transformed the world into a global village [5]. No matter what are the prevailing circumstances, media tends to be a major determinant of the nature of the society through its penetrating power influencing human behavior or habitation [6]. The mediated messages are, therefore, constant stimulants, affecting and shaping attitudes and perceptions and so the ability of decision-making to the desired changes [7].

In the contemporary political ecosphere, media are premium institutes that people depend upon for making the appropriate choice. Media help them cherrypick the most viable option out of multiple alternatives in political narratives. Following its immense potential to set a political agenda media attempts to streamline political discourse influencing the electoral scene in the society [8]. Media circulation of information through its surveillance, interpretation, linkage, correlation, the 
transmission of values and entertainment functions facilitates mass awareness of issues and consequences of all occurring and recurring [9]. People have a multiple-aspect varying information need, one such among them is information about elections, the most sought among the voters. Media not just remain a vital source of crucial election information but also acts as an indispensable facilitator in evolving and shaping popular public opinion through its function of mobilizing and setting the agenda [10].

It builds consensus among the masses through news analysis, debates, studio discussions, opinion polls and surveys [11]. Following greater public participation and an effective feedback system, media empower citizenry though an environment of politically beware decision making amidst prevailing issues and problems in the society [12]. The participatory media provide for effective communication and a deeper understanding of the subject under discussion.

\section{Democracy and Media}

In the words of Knowlton Nash, media act as binding force to connect various power groups in a society, for example, the judiciary, the government mandarins, the elected representatives, the establishment, the business community, and the unions are assumed to be the different kinds of a power center in any democracy and it's the media that link them all together [13]. The mass media as a formidable pillar of democracy provides the potentially vivacious sociopolitical information which vigorous voters may require to a rational stand to support a political idea, consequently to exercise their franchise in favor of any specific person or party [14]. Media modules help detect and locate the problems of society and highlight these various issues to invoke debate and discussion on them by the stakeholders. Therefore, media deliberate between promises and poll plank of the parties and candidates through thorough scrutiny to fix how they view people's problems and what could be the possible political solutions [15]. Hence, among the top priorities of media, identifying the most relevant issues, surveillance of socio-political conditions, securing a common platform for discourse on a range of issues, fixing accountability of the officials involved in the political process for their use or abuse of authority, and resist or restrain the forces outside the media willing to sabotage its own freedom [16]. In a democracy, people are supreme and sovereign with their absolute and independent right to vote and elect. The franchise to choose the candidate of their choice tends to be the base for a democratically elected Government. Freedom of choice remains at the core of a functional democracy where elected representatives act as the nominee of the people in the Parliament to frame laws for them and therefore, right to equal participation, right to contest, campaign and vote, right to debate, dissent and deliberate, universal adult suffrage and periodic elections with multi-party political system, considered as compulsory construct of the constitutional canons cementing the democratic structure [17].

Media educated votaries help operationalize a multi-party system because it educates the people on the pros and cons of various political outfits including their agenda, ideology, priorities, prominence and other outstanding features. Media also specify how and why voting is important for people and therefore, it ensures they have the right to cast vote, contest and campaign independently. The watchdog role of the media ensures that citizens not being discriminated against their caste, creed, race, religion, sex, or ethnicity [18].

\section{Need for the study}

An effective media vigil expedites checks and balances to ensure the transparency of three organs of government, legislature, executive and judiciary in order to enable the uncluttered functioning of a democracy. The undertaken study examines the role played by media during the 2014 Indian general elections with specific reference to its coverage of various political parties involved. The objective of the study includes tracing media frequency and pattern in its coverage during the entire election exercise of the 2014 general elections held in India. The study may contribute to the understanding of the media reporting dynamics and pave the way for further work in the area of politics and media in sub-continent as well as world politics.

\section{METHODOLOGY}

The methodology of qualitative and quantitative content analysis has been applied, however, a mixed method of research dealing with frequencies has been adopted by the researcher. Therefore, the work aimed at exploring the selected print media content to make valid inferences with qualitative and quantitative approaches.

\section{LITERATURE REVIEW}

The available literature on political knowledge focuses on a wide variety of issues like the correlation between reliance on different forms of communication resources and the corresponding level of political knowledge [19]. In his study, Tedesco [20] found a positive relationship between the public issues agendas set by the media and the poll plank of candidates with particularly strong correlations for Republican candidates. With the advancement of the internet revolution, more and more scholars have studied the media as a platform for voicing a public opinion [2123]. Golan and Wanta [24] in their study in New Hampshire for the year 2000 found that second-level agenda setting was primarily important in the initial stages of the campaign when the mass public was beginning to learn about the candidates. Media impact on elections, political participation and voting behavior has been studied in many countries including the United States, UK, Germany and other European and African 
countries but in India, research attention has been focused of late. There have been a few studies on the nature and functions of the media [25-29].

The conclusion suggested that so far in India there had been only a few studies on the media coverage of general elections. Therefore, there is a huge research deficit in which the undertaken study has attempted to analyze the political participation and media reportage in India.

\section{Media and Elections}

A democracy is operationalized by free and fair timely held elections without which it cannot be imagined. In a democratic form of government, it is mandatory that voters are well aware and informed in order to cast their votes to the best and suitable party and candidate [30].

Given to multiple socio-political factors that influence the voting pattern in a democracy as large as India, various socio-economic elements such as caste, religion, region, race, background and persona of candidates, party's ideology has enormous clout. Mass media can affect the voter's mind-set [31] with huge media proliferation and the advent of newer modes of mass media. Politicians and political parties are desperate to even more effective means of reach out to maximum numbers of people opt for these latest media means. Mass media interventionism has brought a drastic change in the political process where citizens enjoy unprecedented freedom of choice to opt-out of multiple choices through extensive, aggressive and analytical media campaigns of the election.

Media theorists assume that popular media means thrive to usher political diversity and multifaceted progress and variety of communication channels and their content would possible and shape democratic values [32]. Such a notion establishes media into the social forces widening the scope of democracy to bring in pluralism, equality, tolerance and civic outlook that can influence the lives of the people. In elections, politicians or parties use media to propagate their agenda, ideology or program charter to seek maximum public support. They offer their schemes and promote their manifestos and pronounce them as the most viable best option among many. Thus media helps in highlighting the various facts and figure with appropriate data about different groups and putting forward the ultimate truth in the public domain [33].

Hence, when people elect their representatives, the outcome of the elections suggests that the media availed them the necessary information to make a sensible choice concerning the suitability of candidates to officiate the positions of authority. As suggested by thinkers one of the key functions of media has been found that they help make images of individuals so as to put in place a line comparison among potential rivals.
Similarly such a constant and continuous publishing results in shaping personality cult and larger than life image following a wider appeal of the media moguls [34]. Such an image make-over was apparently visible how media helped to metamorphose the popular images of prominent politicians including Mahatma Gandhi, Dr. B R Ambedkar, Maulana Azad, Pt. Jawahar Lal Nehru, Indira Gandhi, A B Vajpayee, L.K. Advani, Sonia Gandhi, or Rahul Gandhi, etc. These examples indicate a few names from the Indian political sphere [35]. The immaculate media exposure and flourishing coverage with far-reaching strong appeal may shape and mould the public perception particularly regarding the choice of the suitable candidate which eventually may pressurise a party or political entity to project someone as the face of party or leader in the lead role [36].

\section{Media Impact and General Elections of 2014}

The Indian parliamentary elections of 2014 were a big historic event in the second largest populous country in the world. Indian people voted with great gaiety and fervor to celebrate its vibrant democracy to elect legislatures for the $16^{\text {th }}$ Loksabha. The unprecedented poll exercise with many parties and a huge number of contestants in the ballot battle made it inimitable for many reasons. The titanic exercise was considered to be the largest and longest elections in the world that included 814.5 million voters particularly 23.1 million or $2 \%$ of the population as first-time voters between 18-19 years age group. Remarkably, in the elections, voters participated in huge numbers and witnessed a turn out breaking records of the past with as much as $66.38 \%$ of the total electorate. A total of around 8251 candidates contested for the 543 constituencies during the elections held in 9 phases covering 29 States and 7 Union Territories. Along with many other regional parties BJP and Congress, the two political major parties dominated the political clout of the country. The election coverage includes news largely about the two major political parties for their warring rivalry, attack, counter-attack, agenda, ideologies, policies and strategies, rhetoric and poll planks were all the point of reporting for media outlets. The ruling Congress appeared to be struggling to retain the power due to inescapable anti-incumbency and public rant for alleged misrule and poor governance whereas the main opponent BJP clearly seemed to be in a strong position to contest on multiple political and social fronts. So as many anticipated the right-wing political party BJP following its strong ideological appeal and new development model along-with the cooperation from its allies won the elections and NDA came to power with thumping and impressive victory with 336 seats. Thus the grand old party Indian National Congress which remained the Centre of the power for more than six decades suffered a humiliating defeat with just $8.1 \%$ (44) seats in a house of 543 seats. The Congress rout out reduced the party to its lowest tally ever. The party falls short of winning enough seats 
(10\% seats) required to claim the post of leader of opposition in the parliament. The political consequences echoed with all-pervasive media reports in India during the general elections of 2014 [37]. Multiple media means including conventional media i.e. Newspapers, Radio, News channels or other print or electronic media or social media outlets (Twitter, Facebook, and Instagram) were aggressively exploited to promote and project parties and their policies particularly by opposition parties. The mainstream media had shown a remarkable paradigm shift in reporting the election campaigns extensively about various aspects with its political narrative out of prevailing problems including corruption, economic slump, poor governance, safety and security, health and hygiene or gender justice, etc. Media, therefore, placed the public welfare agenda on the political table unanimous with the mood of the nation during the electioneering [38].

Media with its immense potential construct images of the political parties and leaders through information function. Media machinery through its deep and thorough analysis, assessment and explanation of governance set the popular images of politicians and parties [39]. In the context of 2014 parliamentary elections in India, the pre-election period reporting of media debate and discussion swirl around the performance evaluation and compare of various BJP ruled states such as Gujarat, Chhattisgarh, MP and Goa with the non-BJP ruled states including Uttarakhand, Karnataka, Kerala, Bihar, Tamilnadu and Bengal, etc. ruled by Congress party or others. The 2014 general elections were the exciting film of the fierce fight of ideologies of the parties, poll planks, poll planings, hysteria, rhetoric, ideas and their counter ideas. The historic event witnessed the verbal wars of political rivals including major players of the election providing news content mix to mainstream dailies to vernacular to local outlets. On the one side, the ruling congress party charged its opponent BJP for its communal and dividing agenda based on religious lines to polarise the people, on the other hand, BJP questioned the ruling congress party for appeasement politics and poor governance marred by scams and scandals. In the midst of BJP and congress contest with slogans and rhetoric, media played out a crucially strenuous role letting people into calculations and discussions to research and refine. Media was seen exceptionally exultant and obligated during the general elections of 2014 while reporting political affairs from every nook and corner of the country. It appeared too effective to set the political agenda than its coverage news about developmental issues or common pubic problems. The frequently media strewn news about the inter-party mudslinging, allegations and counter-allegations or leaders trading personal and political jibes persisted pervasively. The observations suggest that pre-election coverage was dominated by news related to crime, corruption or the failure of the government as against the reportage on development communication. In 2014 parliamentary elections following high voltage media reporting and allegations of polarisation, the BJP won landslide mandate with a clean sweep in many states including Delhi, Uttarakhand, Rajasthan, Gujarat and Himachal Pradesh. The BJP won not only the majority of the constituencies of the Hindi belt of the country in the states of UP, Bihar, Jharkhand, MP and Chhattisgarh [40] but also got highest vote share. Media high pitched reporting during general elections 2014 was a big social development where it keenly focussed on political entities and individuals including Narendra Modi, Soniya or Rahul Gandhi among many others. Meanwhile, major public concerns at the ground level, for example, Health, Education, Unemployment or Poverty were not discussed extensively. Therefore, focussed media coverage of political leaders turned the elections into a presidential contest between Modi and rest. The BJP leader and PM Candidate Narendra Modi emerged as poster boy and champion of headlines given to high voltage campaign with his sharp political skills, powerful oratory, strong speeches \& mass appeal presenting him with a larger than life image outweighing the other political constituents. Such an indispensable effect of this mediated publicity or rhetoric cultivated a Modi wave. The pressure of the Modi wave largely formed on the basis of public opinions ultimately projected him the most probable next head of the nation. Media predominantly concentrated on person-specific coverage to hammer on personalities while remaining indifferent to the various issues of social significance. Hence, several other electoral dynamics such as the pertinence of candidates in constituencies, local alliances, and the various state governments and their functioning went underreported [38].

World-famous writer Noam Chomsky and Edward S. Herman, in their illustrious work "Manufacturing Consent: The Political Economy of the Mass Media" in 1988, brought into notice the 'propaganda' and 'systemic biases' and its impact on the mass media. Under the propaganda model, they described how consent is manufactured among the masses on various socio-economic and political problems [41]. The poll analysts across the spectrum hold the opinion that in the absence of a strong \& diverse communication medium, it's not possible to garner support in a country as large as India. Hence, in the general elections of 2014, they believe, its impeccable role of media which opinionated masses and that subsequently went in favor or against a party. Media remained a vital factor and most powerful force affecting outcomes with its potential outreach through news circulation and propagation. It was its tremendous appeal that before even assuming the office BJP PM Candidate Narendra Modi himself in post-poll first-ever press conference acknowledged the significant role of media in his journey from Gujarat to Delhi [42]. The narration outlines that the media-generated powerful 
appeal coupled with strong party rhetoric turned into a wave that dominated public space helped Modi emerged as the most popular and capable person to head the nation as Prime Minister of India [6].

The coverage of general election 2014 by the two major Hindi dailies Amar Ujala and Dainik Jagran can help understand the media trends of election reporting, its attitude towards political parties and national agenda. For this sample of the newspapers Amar Ujala and Dainik Jagran, for the month of April were studied which includes the coverage of the campaign one week before the date, elections started and reporting during the elections till April 30, 2014. The data including thirty days reporting has been analysed for the purpose to study media reporting devoted to the general election 2014. The political news stories on the Front-page and editorial page were the units of analysis for the purpose of inferences the researcher has drawn to study the media campaign during the elections.

\section{Amar Ujala}

The paper was selected because of being among the highly circulated vernacular dailies. Since the majority of Indian population stay in the Hindi belt where Hindi dailies have a far-flung reach to rural and remote arias compared with other language newspapers. The Hindi media has mass appeal among the majority of the Indians owing to their demographical situation. Hence general elections 2014 were a major event for the vernacular Hindi press following its vast exposure to the majority of the Indian voters. Amar Ujala devoted a sizable portion of the space to the political news on its front page and editorial page. The coverage analysis depicts stories to both major parties appeared prominently while comparatively lesser coverage to regional political parties, the paper reported excessively about the two major players, their leaders and their interparty comments, statements and announcements, policies and strategies.

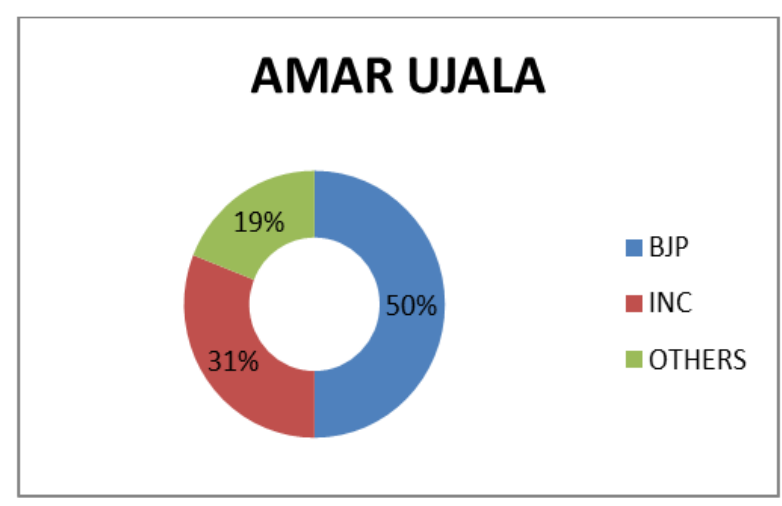

Source: Amar Ujala, April 2014
The above diagram clearly depicts as principal opposition party BJP occupied larger media space in the coverage. Out of total stories counted fifty percent were about the BJP rest thirty-one percent to ruling Congress and nineteen percent were allotted to regional parties and other political or election-related news. Among the news stories that appeared about BJP were largely about the development and good governance which was the main poll plank of the party.

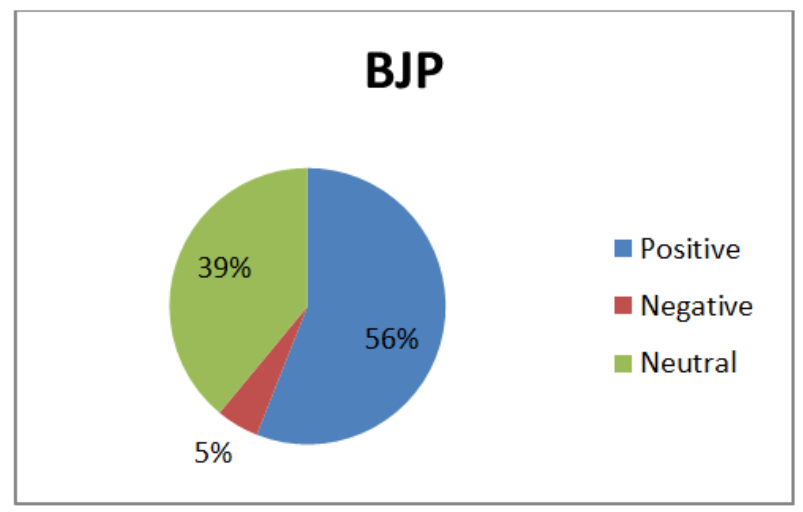

Source: Amar Ujala, April 2014.

The party PM candidate Mr. Narendra Modi was in the focus following his potential development work in Gujrat and presenting a development and good governance model before others, News space was also dominated by news pertaining to his strong and stable leadership, investment-friendly policies, statement from the party leaders, party manifesto or various poll predictions in which party was much ahead against its main opponent INC (Indian National Congress).

The paper also reported about opposition charges on Mr. Modi for 2002 post-Godhra riots when he was the chief minister of Gujrat that he could not control rioting mobs, apart from this news also appeared about party allegedly being involved or provoking sectarian division, communal hate, and polarisation. Thus In news framing, fifty-six percent positive tone of the paper was observed while thirtynine percent negative news appeared with just five percent neutral news make it to the reporting about BJP. Whereas news stories about INC were that of the lack of leadership, corruption-ridden governance following scams including 2G, Coalgate or Adarsh Society and opposition's charges of policy paralysis, dynasty politics or family legacy or diarchy (two power center), weak Prime Minister or bringing low to the office of the PM. However, the news was also reported when party leaders took on BJP for its divisive politics and for the secular credentials of the party accommodating all sections of the society. Of the total news stories appeared about the Congress sixty seven percent negative in tone while twenty-one percent was positive and twelve percent was neutral. 


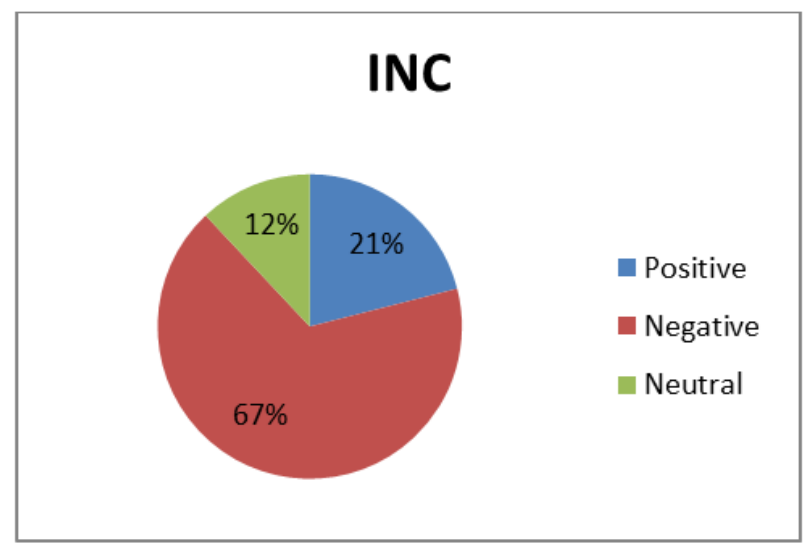

Source: Amar Ujala, April 2014

Thus the overall study of the political news framing of the Amar Ujala with reference to Congress and BJP indicates that BJP was leading in media campaign following more positive news appeared about the party poll prospects, policies and strong leadership under Narendra Modi while at the same time incumbent INC was struggling because of several charges and allegations of corruption, women security, unemployment, inadequate social security and poor socio-economic policies.

\section{Dainik Jagran}

The newspaper is one of the most read news daily with the highest circulation in the northern Hindi heartland of the country. The paper is ranked among the top vernacular dailies with the largest readership across the nation. The newspaper carried out the 2014 general elections reporting with utmost zeal and focus. The coverage dedicated to BJP was mainly about party agenda, news about party's stand on culture, national security, economy, development apart from news on party manifesto and its prime ministerial candidate including his development-oriented decisive politics, strong leadership and equations with other parties. Similarly, the newspaper also allocated considerable coverage to the opposition parties charging him in his controversial role in 2002 Post Godhra riots, corporatefriendly attitude and promoting capitalistic tendencies edging farming or marginalized sections, controversial speeches and statements by the party leaders raking religious sentimentalities in order to polarize the voters etc. The newspaper reporting of the INC (Indian National Congress) include party stand on secularism, inclusivity, scenario of post-poll allies equations given to its secular stand beside news about slacking of decision making, craving corruption and inept governance, questions on party policies and implementation amid multiple opposition allegations or news of party grappling with many scams simultaneously etc. The newspaper also covered the opposition charges of specific policies and misadventures compromising economic development, national security, scandals and policy paralysis etc.

\section{DAINIK JAGRAN}

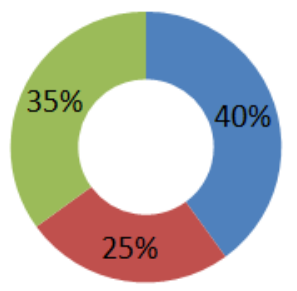

BJP

- INC

OTHERS

The newspaper has carried out a comprehensive coverage dominated by northern political affairs following its linguistic appeal. The newspaper devoted, as visible in the above figure, a maximum coverage share to BJP $40 \%$ beside Congress and Regional parties $25 \%$ and $35 \%$ respectively. As evident, the newspaper allocated a sizable portion of the total coverage to regional parties outnumbering the mainstream ruling Congress party. The category for regional parties and their party affairs has been coded as OTHERS. It's an umbrella term to count stories to cover the regional parties and their leaders, their political affairs or inter-party political activities and discourses. The two national parties BJP and INC were the major players in the election hence both parties were given maximum space collectively by the newspaper. The principal opposition party BJP not only dominated over ruling party INC in total coverage but also the newspaper toned favourably in news framing to depict the positive, negative, neutral aspect. The overall news framing put the BJP much ahead of its main challenger INC. Total Forty-six percent positive news appeared for BJP whereas it was fifty-two percent negative beside it was just two percent neutral as measured for the party.

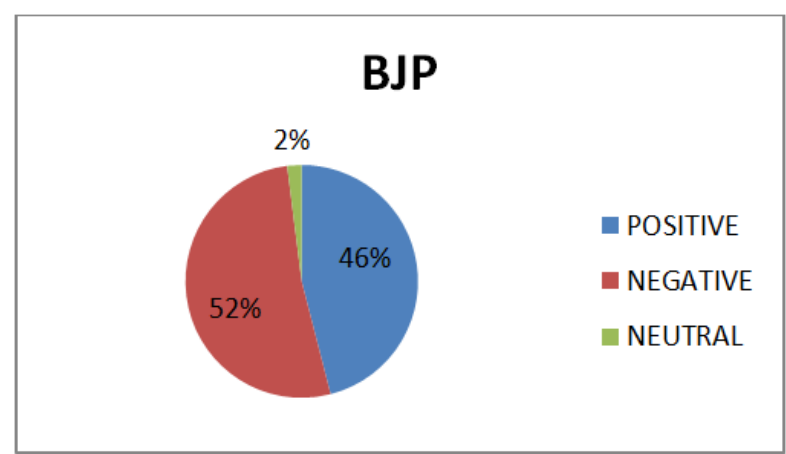

Source: Dainik Jagran, April 2014

The ruling congress seemed to confront the multiple questions and acute anti-incumbency for the previous two consecutive terms under UPA I and UPA II and so it was under huge pressure for the accountability of its government on multiple national and international concerns. Although it also had got 
positive reportage for its secular character well positioning it to get post-poll alliances with ease yet it remained under severe anti-incumbency for its consecutive ten years in power.

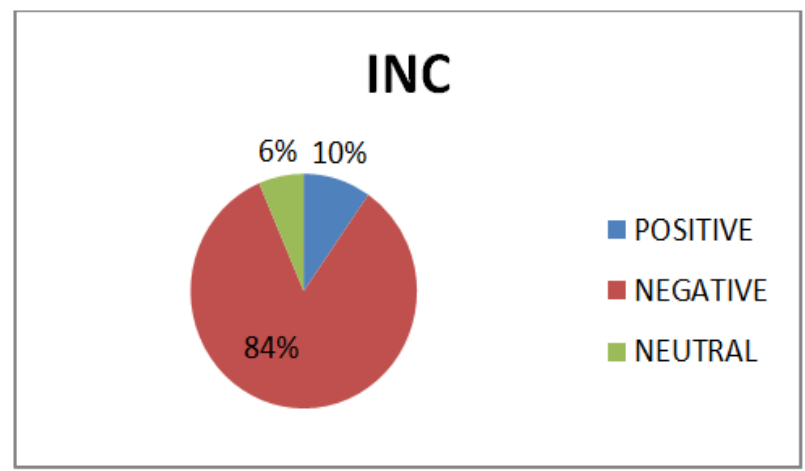

Source: Dainik Jagran, April 2014

The tone of the newspaper in its coverage of INC well demonstrates how it was edged out by its main opponent BJP. Its negative news percentage stands as high as fifty-four percent with just thirty-two percent positive and fourteen percent neutral. The overall tone of the newspaper analysis and framing suggest BJP always stood at an advantage from the reporting perspective with a far-reaching appeal to the voters while larger reporting about the congress remained unfavourable owing to the adversity, hostility and accountability of the party for its rule of the last ten years. The news about congress mainly appeared about the opposition charges and questioning the party for its multi-pronged failure including national security, economic slump, unemployment, price hikes, corruption, health and poverty, etc.

\section{CONCLUSION}

Mass Media is one of the most important institutions in the contemporary society that fulfills the communication needs of the people through its vital role in keeping the citizenry updated of the current events and raising awareness of various issues. Media as one of the strongest pressure groups, having a direct influence on the political process, acts as a mediator between peoples and institutions through which public opinion is shaped and at times manipulated. It is the resilient pillar of democracy enabling it to keep up to the ambitions and hopes of the public particularly in electoral politics where media plays as a crucial player with its unparalleled reach and approach to the voting groups. It plays out an exceptionally active and significant role in politics and let out no effort to ensure transparency and good governance in a democratic institutional arrangement. A functional democracy can not smoothly run unless it is supported by free and powerful media which pushes for the various social values and relentlessly strive for social amity, equity and welfare of the people. In a democratic form of government, elections in the absence of independent and strong media are equated with the violation of natural adjudication. Media, democracy or elections are broad subjects that are interlinked and interdependent mainly in the context of electoral politics that poses a formidable challenge to the media in its impartiality and objectivity to the test.

The media reporting during the general elections of 2014 was distinct in multiple means including its all-pervasive and wide-ranging coverage to sensitize the masses about striking and sparking electoral politics of the world's largest democracy. The two major national parties - Indian National Congress (INC) commonly called the Congress party, and the Bharatiya Janata Party (BJP) - remained much ahead of the other parties in the overall coverage of the campaign during the elections. As suggested by coverage, the BJP appeared to be more aggressive than rival the Congress in the media buzz. In sharp contrast to the past when media was focused mainly in parts of urban India, this time media coverage went far deeper to rural India prominently to connect the voters with this mega democratic fest of electing parliamentary legislatures. The participating political parties seemed to have been fascinated by the presidential model of campaigning in the US where beside media machinery, thousands of volunteers worked to mobilize the voters. In the election campaign, major political parties, as well as high profile contestants in selected constituencies, remained in the center of reporting for the media to expose to the voters. The contentious coverage of selected media came into question following unbalanced image projection of political bigwigs including Rahul Gandhi, Sonia Gandhi, Narendra Modi, etc.

The mainstream media, especially vernacular press, should not be slanted neither it should act as a mouthpiece of any party either in power or in opposition. In most possible ways, media must remain a platform for a free and balanced flow of information to the masses. It should function proportionally and objectively without any favor or fear. It should not act as a blind critic or supporter of any political party rather it must act as a constructive critic. Its foremost function must be to enlighten, educate and inform the people for thought-provoking debates and discussions in the light of ongoing political or apolitical adventures. It must review the relationship between politics and people's priorities for it is also accredited as custodian of democracy. Such a relationship requires constant rebalancing for ultimate transparency and constant critical assessment as civic society requires practicality and balance between media and politics for the sustenance, success and smooth operational democratic system. 


\section{REFERENCES}

1. Jethwaney JN. Mass Communication Education. In Whither Journalism \& PR Education?: A Symposium on Indian Scene (p. 92). University Book House. 2001.

2. Dayal K. Mass Communication in Information Age. New Delhi: Cyber Tech Publications. 2011.

3. McCombs M. The agenda-setting role of the mass media in the shaping of public opinion. In Mass Media Economics 2002 Conference, London School of Economics; 2002, June: http://sticerd. 1se. ac. uk/dps/extra/McCombs. pdf.

4. Lodge J. Transparency and democratic legitimacy. Journal Common Mkt. Stud. 1994; 32:343.

5. Tresilian N. Media and Information Technology: The Day Kennedy Died... and After. Time \& Society, 1995;4(2), 261-270.

6. Upadhyay V. Livemint. 2013, August 26. Retrieved October 25, 2015, from http://www.livemint.com/Consumer/XU1EhHP3O 5EYJRg3wQGD9M/Election-campaign-partiesdraw-battle-lines-on-media-platfo.html

7. Bandura A. Social cognitive theory of mass communication. In Media effects; 2009;110-140. Routledge.

8. Banis D. Fictiocracy: Media and politics in the age of storytelling. Institute of Network Cultures. 2018.

9. Anand S. Mass Communication and Journalism. New Delhi: Upkar Prakashan. 2012.

10. Weaver D. Media agenda setting and elections: Voter involvement or alienation?. Political Communication, 1994;11(4), 347-356.

11. Woodly D. New competencies in democratic communication? Blogs, agenda setting and political participation. Public Choice, 2008;134(12), 109-123.

12. Jenkins H, Ford S, Green J. Spreadable media: Creating value and meaning in a networked culture (Vol. 15). NYU press; 2018.

13. Young WD. The Voices of Democracy: Politics and Communication in Canada. Canadian Journal of Political Science/Revue canadienne de science politique, 1981;14(4), 683-700.

14. Street J. Mass media, politics and democracy. Macmillan International Higher Education. 2010.

15. Curran J, Hesmondhalgh D. Media and Society. Bloomsbury Academic. 2019.

16. Elliott D. Foundations for news media responsibility. Responsible journalism, 1986;3244.

17. Gunther R, Mughan A. (Eds.). Democracy and the media: a comparative perspective. Cambridge University Press. 2000.

18. Lichtenberg J, MacLean D. (Eds.). Democracy and the mass media: a collection of essays. Cambridge University Press. 1990.
19. Berkowitz D, Pritchard D. Political knowledge and communication resources. Journalism Quarterly. 1989 Sep;66(3):697-701.

20. Tedesco JC. Um pequeno grande mundo: a família italiana no meio rural. ACIRS; 2001.

21. Hook GD, Gilson J, Hughes CW, Dobson H. Japan's international relations: politics, economics and security. Routledge; 2011.

22. Krueger JG. The immunologic basis for the treatment of psoriasis with new biologic agents. Journal of the American Academy of Dermatology. 2002 Jan 1;46(1):1-26.

23. Krueger RF, Markon KE, Patrick CJ, Iacono WG. Externalizing psychopathology in adulthood: a dimensional-spectrum conceptualization and its implications for DSM-V. Journal of abnormal psychology. 2005 Nov;114(4):537.

24. Wanta W, Chang KK. Visual depictions of president in the international press after the release of the starr report. Visual Communication Quarterly. 2001 Jun 1;8(3):9-14.

25. Fernandez-Duque D, Baird JA, Posner MI. Executive attention and metacognitive regulation. Consciousness and cognition. 2000 Jun 1;9(2):288-307.

26. Johnson SG, Joannopoulos JD. Block-iterative frequency-domain methods for Maxwell's equations in a planewave basis. Optics express. 2001 Jan 29;8(3):173-90.

27. Kluver $\mathrm{R}$, editor. The Internet and national elections: A comparative study of Web campaigning. Taylor \& Francis; 2007.

28. Prasad K. Media Law and Ethics: Readings in Communication Regulation. Delhi: B.R. Publishing Corporation. 2008.

29. Sonwalkar N. Changing the interface of education with revolutionary learning technologies. Syllabus Magazine. 2001 Nov.

30. Howard R. Media and Elections: An Elections Reporting Handbook. (A. Gibbs., Ed.) Institute for Media, Policy and Civil Society. 2004.

31. Benoit WL. The handbook of election news coverage around the world. Journal of communication. 2009.

32. Dahl R. Who Governs? Democracy and Power in an American city. New Haven: Yell University Press. 1982.

33. Weaver DH. What voters learn from media. The Annals of the American Academy of Political and Social Science, 1996;546(1), 34-47.

34. Mughan RG. Media and the Democracy; A comparative perspective. Critical Media Studies. 2000.

35. Gandhi J, Sandhu V. Rahul. New Delhi: Penguin Group. 2012.

36. Hopmann DN. Effects of Election News Coverage: How Visibility and tone Influence Party Choice. Political Communication, 2015;389-405.

37. Wallace P. (Ed.). India's 2014 Elections: A Modiled BJP Sweep. SAGE Publications India. 2015. 
38. Hasan Z. Retrieved October 25, 2015, from The Hindu center; 2014, April 2: http://www.thehinducentre.com/verdict/commenta ry/article5843621.ece

39. Craig G. The Media Politics and Public Life. Australia: Allen \& Unwin. 2004.

40. Sinha AK. Retrieved November 06, 2015, from The Indian Express; 2014, May 16: http://indianexpress.com/article/india/politics/verdi ct-2014-modi-wave-a-thumping-win-and-someclean-sweep-for-bjp/

41. Herman ES, Chomsky N. Manufacturing consent: A propaganda model. Manufacturing Consent. 1988.

42. Narita. Oneindia. 2014, May 17. Retrieved October 25, 2015, from http://www.oneindia.com/india/lok-sabhaelection-results-2014-how-indian-media-reacts-tonarendra-modi-s-victory-1449520.html 